Olivet Nazarene University Digital Commons@ Olivet

Faculty Scholarship - Family and Consumer

Science

Family and Consumer Science

Fall 2012

\title{
A Review of Health Literacy and Its Relationship to Nutrition Education
}

Heather Diane Gibbs

Olivet Nazarene University, hgibbs@olivet.edu

Karen Chapman-Novakofski

University of Illinois at Urbana-Champaign, kmc@illinois.edu

Follow this and additional works at: https://digitalcommons.olivet.edu/facs_facp

Part of the Dietetics and Clinical Nutrition Commons, and the Human and Clinical Nutrition Commons

\section{Recommended Citation}

Gibbs, Heather, and Karen Chapman-Novakofski. "A Review of Health Literacy and Its Relationship to Nutrition Education." Topics in Clinical Nutrition 27.4 (2012): 325-333.

This Article is brought to you for free and open access by the Family and Consumer Science at Digital Commons @ Olivet. It has been accepted for inclusion in Faculty Scholarship - Family and Consumer Science by an authorized administrator of Digital Commons @ Olivet. For more information, please contact digitalcommons@olivet.edu. 


\section{A Review of Health Literacy and its Relationship to Nutrition Education}

\section{Heather Gibbs, PhD, RD, LDN}

Karen Chapman-Novakofski, PhD, RD, LDN

Accepted for publication in the October-December 2012 issue of Topics in Clinical Nutrition, vol. 27, no. 4, pp. 325-333.

\section{Introduction}

The United States (US) Department of Health and Human Services (2000) and the Institute of Medicine (2004) have defined health literacy as "the degree to which individuals have the capacity to obtain, process, and understand basic health information and services needed to make

appropriate health decisions" ${ }^{\text {(pp.32) }}$. The term encompasses all of the skills a person needs in order to make positive health choices, and clearly involves more than literacy alone. Obviously, nutrition is one important sector of health care where education is needed, but understanding what comprises a healthful diet is complex and may require high cognitive skills. Unfortunately, there is little discussion of health literacy among nutrition literature, so this review attempts to translate the concept of health literacy into the context of nutrition in order to provide the dietitian with a better understanding of how health literacy impacts nutrition practice.

\section{Background}

In 2004, the Institute of Medicine (IOM) brought the issue to national attention in its report, Health Literacy: A Prescription to End Confusion. This report states that "people with low health literacy have less knowledge of disease management and of health-promoting behaviors, report poorer health status, and are less likely to use preventive services" ${ }^{\text {(pp.8) }}$. Further, it is considered a patient's right to understand his/her healthcare options and plan of care. The Joint Commission on Health Care Accreditation measures compliance of healthcare facilities on 
several issues including Patient Safety. Poor health literacy among patients makes compliance with these standards difficult because these patients have limited understanding of their health care $^{2}$.

Results of the National Assessment of Adult Literacy (NAAL) showed that only $12 \%$ of those surveyed had proficient health literacy, which means the majority of Americans exhibit some level of difficulty in managing their health care. The study identified $14 \%$ of participants who had below basic health literacy skills, defined as "no more than the most simple and concrete literacy skills," and $22 \%$ of participants had basic health literacy skills, defined as "skills necessary to perform simple and everyday literacy activities" ${ }^{\text {(pp.5) }}$. The IOM estimated nearly half of Americans have difficulty understanding and making choices for their health care ${ }^{1}$.

Some demographics have been identified in order to better understand the population subgroups that may experience a higher rate of limited health literacy. In terms of ethnicities, the NAAL reported that Hispanic adults had lower average health literacy compared to any other racial/ethnic group, while White and Asian/Pacific Islander adults had higher average health literacy. Adults living at or below the poverty level and adults over 65 years of age averaged lower health literacy scores. In this older age group, $29 \%$ were found to have below basic skills and $30 \%$ were identified having basic skills ${ }^{3}$. This last dynamic is particularly striking considering the number of patients who fall into this age category. For all Americans, this population group accounts for $12 \%$ of the total population with expected growth to $20 \%$ in $2030^{4,5}$, and with hospitalization rates three times that of any other age group ${ }^{6}$.

\section{Consequences of Poor Health Literacy}


The consequences of poor health literacy reach beyond the individual, affecting the larger health care environment. The IOM ${ }^{1}$ identified four general relationships between health care and reduced health literacy including decreased knowledge of illness and management ${ }^{7}$, increased hospitalization rates ${ }^{8}$, decreased use of preventive care services ${ }^{9}$, and increased cost of health care $^{10}$.

More than other chronic diseases, relationships between health literacy and diabetes have been reported in literature. Reduced health literacy is common among those with diabetes, with estimates between $51-63 \%$ of the diabetes population ${ }^{7,11,12}$ and low literacy is particularly common among those with poor glycemic control ${ }^{13}$. Diabetes requires extensive self-care in many cases, making it a logical target for health literacy research.

\section{Health Literacy and Diabetes}

Schillinger and colleagues ${ }^{11}$ were among the first to report that reduced health literacy negatively impacts outcomes in those with diabetes. Participants $(n=408)$ in this study were evaluated for health literacy by S-TOFHLA (shortened Test of Functional Health Literacy in Adults) and glycemic control by hemoglobin A1c (HbA1c). Glycemic control was categorized as tight ( $\mathrm{HbA} 1 \mathrm{c}$ of $7.2 \%$, or $25 \%$ ile cut point for study population) or poor (HbA1c of $9.5 \%$, or 75th\%ile cut point for study population). In those with inadequate health literacy, 30\% had poor glycemic control compared with only $20 \%$ of those with adequate health literacy $(\mathrm{P}=0.02)$. They also found that "for each one point decrement of the S-TOFHLA, HbA1c increased by 0.02 $(\mathrm{P}=0.02)$ " indicating a direct relationship between the two measures.

Evidence is mounting that those with diabetes and reduced health literacy are less well equipped for self-care. These individuals have diabetes-related knowledge deficits ${ }^{7,14,15}$, where direct 
increases in diabetes knowledge are seen with increases in health literacy ${ }^{16}$. They are also less likely to participate in health care decisions ${ }^{14}$, less likely to keep records of personal glucose testing ${ }^{17}$, and experience hypoglycemia more often ${ }^{18}$. What is more, research suggests that health literacy (as measured by s-TOFHLA), not race, is a predictor of glycemic control $(19,20)$, an important finding because of the disproportionate prevalence of type 2 diabetes among minority populations.

\section{Identification Techniques}

Often, patients are asked to report the last level of school attainment, which many assume would indicate level of literacy. However, studies indicate that the health literacy level is frequently 3 4 years below the highest grade completed ${ }^{21}$. Moreover, the NAAL ${ }^{3}$ reports that of those adult participants with a 4-year college degree, 3\% had below basic health literacy (defined above), which further illustrates the potential for inaccurate assumptions if a clinician considers educational attainment without specific assessment of health literacy. Health literacy may be a mediator between education levels attained and health outcomes ${ }^{22}$, suggesting health literacy, not education level is a more important consideration for health educators.

Few assessments to measure health literacy are available, and each has limitations. The IOM recognized two assessment tools including the Rapid Estimate of Adult Health Literacy in Medicine (REALM) ${ }^{23}$ and the Test of Functional Health Literacy in Adults (TOFHLA) ${ }^{24}$. Both of these tools identify print literacy in the context of health care and are briefly reviewed here, as well as one additional measure, the Newest Vital Sign (NVS) ${ }^{25}$.

\section{REALM}


The REALM ${ }^{23}$ was the first literacy instrument developed for a health care setting. This test consists of three columns of 22 words (totaling 66 words) drawn from a health care context in order of number of syllables and difficulty. Patients are asked to read the words aloud, with notations made by the assessor for correct or incorrect pronunciations or words not attempted. Criterion validity was established for the REALM through correlations between scores for the REALM and for three standardized reading tests. Pearson correlation analysis revealed a significant association between the standardized tests and the REALM $(\mathrm{P}<0.0001)$. Test-retest

reliability was established at $0.99(\mathrm{P}<0.001)^{23}$. Although the REALM is quick, it is limited since it is only a predictor of reading ability, and correct pronunciations of words do not clearly establish understanding.

\section{TOFHLA}

In addition to assessment of print literacy, one of the TOFHLA's ${ }^{24}$ strengths is that it also assesses numeracy, another recognized component of health literacy. The reading comprehension section of the TOFHLA (50 items) involves a method for reading comprehension measurement known as the cloze procedure ${ }^{26}$. For TOFHLA, content validity was established through its use of passages drawn from actual medical literature for patients. Construct validity was established for reading comprehension through Spearman's rank correlation between the TOFHLA and the standardized literacy instrument, Wide Range Achievement Test-Revised ${ }^{27}$ (WRAT-R), $(0.74 ; \mathrm{p}<0.001)$ and the REALM $(0.84 ; \mathrm{p}<0.001)$ for the English version only (neither the REALM nor WRAT-R are available in Spanish). Cronbach's alpha was 0.98 for both English and Spanish versions. Test-retest reliability measured by the Spearman-Brown coefficient was also significant for English (0.92) and Spanish (0.84) versions ${ }^{24}$. 
Unfortunately, the TOFHLA takes up to 22 minutes to administer, which limits its use to

research settings. A shortened version, known as the S-TOFHLA ${ }^{28}$, was later developed, reducing the time estimate for assessment to 12 minutes. Similarly, the S-TOFHLA was also validated against the REALM with significant correlations $(\mathrm{p}<0.001)^{28}$.

NVS

The Newest Vital Sign (NVS) ${ }^{25}$ also measures both literacy and numeracy, requires only three minutes for administration, and consists of a nutrition label with six accompanying questions. Reliability was established for the NVS ${ }^{25}$ by Cronbach's alpha of 0.76 (English) and 0.69 (Spanish). Criterion validity was established against the TOFHLA by Pearson's correlation for English $(\mathrm{r}=0.59, \mathrm{p}<0.001)$ and Spanish $(\mathrm{r}=0.49, \mathrm{p}<0.001)$

\section{Application in Nutrition Education and Counseling}

While each of these instruments can reliably identify individuals with limited health literacy skills, none of them are specific to nutrition. This distinction is important because as Parker and colleagues ${ }^{24(\text { pp.540) }}$ write, "functional literacy is situation-specific: someone's reading skills may be perfectly adequate in one setting and marginal or inadequate in another." Using these assessments in a nutrition education setting may assist the nutrition professional in determining appropriate reading levels of materials, but they cannot provide information as to the individual's nutrition proficiency.

The NVS was used by Zoellner and colleagues ${ }^{29}$ to measure "nutrition literacy" in the study population. Although the NVS utilizes a food label in its assessment, it is not described as a measure of nutrition literacy, but rather of health literacy ${ }^{25}$. The food label purposes to measure numeracy; no questions seek to identify nutrition knowledge. While use of a nutrition label is an 
important skill for making healthful dietary choices, the questions used in the NVS could be answered by someone who has both functional literacy and numeracy but no nutrition knowledge.

The only assessment instrument specific to nutrition literacy presented in the literature is the Nutrition Literacy Scale (NLS) ${ }^{30}$. The instrument was designed to follow the cloze method ${ }^{26}$ for measuring reading comprehension as was used in the TOFHLA and S-TOFHLA. The 28item NLS was completed by 341 patients in three family medicine practices and one integrative medicine practice. Participants in three of these groups also completed the S-TOFHLA for control purposes. The Cronbach's alpha coefficient of 0.84 indicates internal consistency for the NLS but Pearson's correlation between the NLS and S-TOFHLA was only 0.61 for the three groups. Although the author states "the NLS covers the major consumer-related topics in nutrition," 30 (pp.4) the instrument itself is not published and has not been used or discussed further in literature.

\section{Health Literacy in a Nutrition Context}

Nutrition knowledge has been divided into three components including (1) an awareness of the importance of nutrition, (2) knowledge of nutrition principles; and (3) "how to" knowledge ${ }^{31}$. Zoellner ${ }^{29 \text { (pp.1) }}$ proposed that "nutrition literacy" should be defined as "the degree to which individuals have the capacity to obtain, process, and understand nutrition information and skills needed in order to make appropriate nutrition decisions," a definition adapted from the IOM's definition of health literacy. Transposing these two concepts to form a nutrition literacy working definition would include knowledge of nutrition principles (capacity to obtain knowledge) and "how to" knowledge (skills needed). Even as research and practice move forward, albeit slowly, 
in the definition and application of nutrition literacy for individuals, the nutrition literacy of the general population and targeted segments has an ambiguous array of reported awareness, knowledge and application.

\section{Knowledge of Nutrition Principles}

Unfortunately, data describing general nutrition knowledge of the American public is scarce with a lack of focus upon nutrition knowledge in government population surveys since the USDA's Diet and Health Knowledge Survey of 1995. Current surveys largely address nutrition attitudes and behaviors, which may or may not reflect actual nutrition knowledge. Thus, while the 2010 Dietary Guidelines for Americans address continued poor diet quality among the general American population, the nutrition professional is left making assumptions regarding the connection between these behaviors and the knowledge that precedes the behaviors.

One recent survey with some focus on nutrition knowledge is the International Food Information Council's 2011 Food \& Health Survey ${ }^{32}$. Relevant nutrition knowledge data is listed in Table 1. These findings suggest that consumer confusion exists with regard to nutrition concepts. For example, significant portions of the sample report trying to reduce positive nutrients, such as monounsaturated fat and complex carbohydrates and approximately $1 / 3$ are not trying to reduce saturated and/or trans fatty acids. In addition, food group identification for low-income African American women relates more to food preparation rather than the USDA foods ${ }^{33}$. Within the context of nutrition literacy, this limited data suggests some understanding of general nutrition concepts among Americans, such as the need to avoid saturated or trans-saturated fats, but not practical knowledge, such as the ability to identify foods high in saturated or trans-saturated fat or how to group foods. 
An individual's nutrition knowledge may be impacted by individual interest in and methods for obtaining nutrition information. Zoellner ${ }^{29}$ found a strong relationship between "nutrition information-seeking behaviors" and nutrition literacy in her exploratory study of nutrition literacy of adults in the Lower Mississippi Delta, a region with known health disparities. Health/nutrition literacy was measured by NVS, in which they identified $48 \%$ with adequate health/nutrition literacy, while $24 \%$ and $28 \%$ had a high likelihood and a high possibility of limited nutrition literacy, respectively. Additionally, it was learned that the most popular sources of nutrition information for this specific population included television (57\%) and newspapers or magazines (50\%), with only $20 \%$ accessing information online, a source also identified by participants as least trustworthy.

These three sources are the most popular for Americans, according to the ADA's Nutrition and You: Trends 2011 Survey ${ }^{34}$ ( $\mathrm{n}=754$ adults) where television remains the most popular source (67\%) followed by magazines (41\%) and the internet (40\%). Interestingly, participants do not necessarily believe these sources are the most credible; rather, the authors speculate that these sources are chosen because they are most easily accessible. In Canada, food labels were the most common source (67\%), followed by the internet (51\%), and magazines/newspapers $(43 \%)^{35}$.

\section{"How To" Knowledge}

Two researched factors that might be considered "how to" knowledge include food label reading and portion sizing. The Nutrition Facts Panel on a food label provides detailed nutrient information and can, therefore, assist people in making nutritious food choices. Nearly twothirds of Americans are estimated to use the Nutrition Facts Panel of the food label ${ }^{36}$, and it is used more often by individuals who consider the nutrient content of food when choosing food 
products ${ }^{37}$. Not surprisingly then, females read food labels more often than males, with an estimated $28 \%$ of females almost always reading them ${ }^{38}$, and those with diet-related chronic diseases $^{39}$ read labels more often (hypertension $\mathrm{P}=0.021$; hypercholesterolemia $\mathrm{P}=0.005$; diabetes $\mathrm{P}<0.01)$ than those without these diseases. However, research indicates that while people may be able to use food labels to make simple decisions, such as comparing food items for a particular nutrient, they experience more difficulty in making health assessments of foods using information from food labels alone ${ }^{40}$. Indeed, food labels have been emerging with very simple visual symbols reflecting healthfulness because of nutrition literacy issues ${ }^{41}$.

Choosing appropriate portion sizes of foods is widely believed to be an important skill for balancing calorie intake with energy expenditure and is consequently often the subject of nutrition education efforts. Recommended portion sizes are established by the USDA through the Dietary Guidelines for Americans and MyPlate. Huizinga and colleagues ${ }^{42}$ measured portion-size estimation and literacy in 164 participants. Though accuracy varied between foods (pasta, pineapple, cooked ground beef, and cranberry juice), for combined food items, $62 \%$ of participants correctly served a single serving of foods and $65 \%$ correctly served a different specified amount. Estimation was poorer in those with low literacy.

In sum, given that little is known regarding general knowledge of nutrition principles and how to knowledge, assumptions cannot be made regarding nutrition literacy proficiencies in the general population nor in individuals. The responsibility of identifying nutrition literacy proficiency falls to the nutrition professional as a part of the nutrition assessment.

\section{Materials and Interventions for Health Education}


With the apparent negative relationship between health literacy and health outcomes, attention must turn to educational approaches that can overcome this obstacle for patients. Print literacy is only one component of health literacy, but because nutrition education often involves communication through the use of handouts, it is worth discussing here. When written materials are necessary, applying the concept of "plain language" is important. Plain language is generally identified as writing that allows readers to "find what they need, understand what they find; and use what they find to meet their needs" 43 (para.1)

Educational techniques for low health literate populations have been incorporated into the Diabetes Literacy and Numeracy Education Toolkit (DLNET), developed by researchers at Vanderbilt University ${ }^{44}$. These techniques are presented in Table 2.

It is likely that those with reduced health literacy require frequent follow-up ${ }^{45}$. Rothman and colleagues ${ }^{13}$ found that use of these techniques improved HgbA1c values independent of health literacy levels of participants $(n=111)$ with poorly controlled diabetes, but patients received contact by educators every two to four weeks for six months. In a shorter study, lasting 12 to 16 weeks, Wallace and colleagues ${ }^{46}$ report improvements in participants' $(n=250)$ self-care and diabetes-related knowledge regardless of health literacy levels, again providing brief patient contact three times over the course of the study. Similarly, successful nutrition education interventions targeting low-literacy populations have involved a combination of multiple clientprovider contacts along with the use of low-literacy written materials ${ }^{47}$.

\section{Conclusions}


While focus upon the problem of health literacy has increased within general medical literature, discussion remains minimal within nutrition literature. This absence raises the question as to whether nutrition professionals are addressing the problem of health literacy within their care.

Our preliminary survey of three dietetic practice groups (DPGs) of the American Dietetic Association found that $79 \%$ of survey participants $(n=129)$ self-reported they did not use available health literacy assessment tools ${ }^{48}$. One explanation could be that current health literacy assessment tools are inadequate for nutrition professionals because they do not identify a person's nutrition literacy, only print literacy using health-related words and phrases. If Parker and colleagues ${ }^{23}$ are correct, that "functional literacy is situation specific," then techniques for measuring health literacy are likely inadequate to measure nutrition literacy.

If an instrument is developed that reliably measures nutrition literacy, dietitians need to use educational methods that appropriately match the client's nutrition literacy level. However, our preliminary survey of three DPGs, we found that only $21.3 \%$ of participating dietitians reported they "always" have written materials available to meet different levels of understanding.

Another consideration is that different clients may need different nutrition skills based on their need for nutrition information. Our preliminary study involving key informant interviews ${ }^{48}$ suggests a tiered effect of skills needed to understand nutrition education. In general, it was felt that if a disease with nutrition implication is present, the need for nutrition and food-related skills increases. For example, a client with diabetes may need greater proficiency with nutrition literacy due to the complexities of medical nutrition therapy associated with the disease compared with an individual who simply wants to improve overall diet quality. In response, we have developed a nutrition literacy assessment algorithm ${ }^{48}$ for determining if clients need 
macronutrient knowledge; numeracy skills for label reading; household measurement skills for portion sizing; or food group identifications skills. A nutrition professional can use this algorithm to determine which components of nutrition literacy assessment to evaluate based on the type of diet instruction that is required. 
Table 1. 2011 IFIC Foundation Food \& Health Survey: Key Findings Related to Nutrition Knowledge.

\begin{tabular}{|c|c|}
\hline Participants/Methodology & Key Findings Related to Nutrition Knowledge \\
\hline $\begin{array}{l}\mathrm{N}=1,000 \text {, representative } \\
\text { sample of US Adult } \\
\text { Population (18+) on age, } \\
\text { socioeconomic profile, } \\
\text { race/ethnicity, region, and } \\
\text { gender; web survey }\end{array}$ & $\begin{array}{l}\text { - } \quad 9 \% \text { can accurately estimate their recommended calorie } \\
\text { intake } \\
\text { - } \quad 60 \% \text { cannot accurately estimate the number of calories } \\
\text { they burn in a day } \\
\text { - } 40 \% \text { agree that eating more calories than are burned in a } \\
\text { day leads to weight gain } \\
\text { - } 66 \% \text { are trying to limit saturated and/or trans fatty acids } \\
\text { - } 19 \% \text { are trying to limit polyunsaturated fats } \\
\text { - } 17 \% \text { are trying to limit monounsaturated fats } \\
\text { - } 40 \% \text { are trying to limit high fructose corn syrup } \\
\text { - } \quad 17 \% \text { are trying to limit refined carbohydrates } \\
\text { - } \quad 60 \% \text { identify that protein is found in animal sources } \\
\text { - } 47 \% \text { identify that protein is found in plant sources }\end{array}$ \\
\hline
\end{tabular}


Table 2. Suggested Methods for Educational Interventions with Low Health Literate Audiences as Identified through the DLNET Program (Rothman et al, 2004; Wolff et al, 2009) (Adapted with permission):

- Focus on selected critical behaviors

- Reduced complexity of health information

- Concrete examples

- Limited number of topics per educational session

- Avoid jargon

- Employ the "teach-back" method (Educator teaches a concept or skill through explanation or demonstration. The client is then asked to teach the educator the same concept.)

- Print information at $4^{\text {th }}$ to $6^{\text {th }}$ grade reading level

- Picture-based information

- $\quad$ Shared goal setting 


\section{REFERENCES}

1. Neilson-Bowman, Lynn. Institute of Medicine. Health Literacy: A Prescription to End Confusion. Washington, D. C.: National Academies Press; 2004.

2. Murphy-Knoll, Linda. Low health literacy puts patients at risk: The Joint Commission proposes solutions to national problem. J Nurs Care Qual. 2007;22(3):205-209.

3. U.S. Department of Education. The health literacy of America's adults: Results from the 2003 national assessment of adult literacy. 2006. http://nces.ed.gov/naal/. Accessed November 9, 2010.

4. He, W., Sengupta, M., Velkoff, V., \& DeBarros, K. 65+ in the United States. U.S. Census Population Reports. 2005; http://www.census.gov/prod/2006pubs/p23-209.pdf . Accessed March 26, 2008.

5. Schwartzberg, JG., VanGeest, JB, \& Wang, CC. (Eds.). Understanding Health Literacy. Chicago, IL: American Medical Association; 2005.

6. Administration on Aging. Profile of Older Americans 2009. http://www.aoa.gov/AoARoot/Aging_Statistics/Profile/2009/14.aspx . Accessed November 9, 2010.

7. Williams MV, Baker DW, Parker RM, Nurss JD. Relationship of functional health literacy to patients' knowledge of their chronic disease. Arch Intern Med. 1998;158:166172.

8. Baker DW, Gazmararian JA, Williams MV, et.al. Functional health literacy and the risk of hospital admission among Medicare managed care enrollees. Am J Public Health. 2002;92(8):1278-1283. 
9. White S, Chen J, Atchison R. Relationship of preventive health practices and health literacy: A national study. Am J Health Behav.2008;32(3):227-242.

10. Eichler K, Wiser S, Burgger U. The costs of limited health literacy: A systematic review. Int J Public Health. 2009;54:313-324.

11. Schillinger D, Grumbach K, Piette J, Wang F, Osmond D, Daher C, Palacios J, Sullivan GD, Bindman AB. Association of health literacy with diabetes outcomes. JAMA. 2002; 288:475-482.

12. Rothman R, Pignone M, Malone R, Bryant B, Horlen C, Padgett P. The relationship between health literacy and diabetes related measures for patients with type 2 diabetes. $J$ Gen Intern Med. 2002;17(suppl 1):167.

13. Rothman R, Malone R, Bryant B, Horlen C, DeWalt D, Pignone M. The relationship between literacy and glycemic control in a diabetes disease-management program. Diabetes Educ. 2004;30:263-273.

14. DeWalt DA, Boone RS, Pignone MP. Literacy and its relationship with self-efficacy, trust, and participation in medical decision making. Am J Health Behav. 2007;31(Suppl 1)S27-35.

15. Powell CK, Hill EG, Clancy DE. The relationship between health literacy and diabetes knowledge and readiness to take health actions. Diabetes Educ. 2007:33(1):144-51.

16. Mancuso, J. Impact of health literacy and patient trust on glycemic control in an urban USA population. Nurs Health Sci. 2010;12:94-104.

17. Mbaezue N, Mayberry R, Gazmararian J, Quarshie A, Ivonye C, Heisler M. The impact of health literacy on self-monitoring of blood glucose in patients with diabetes receiving care in an inner-city hospital. J Natl Med Assoc. 2010;102(1):5-9. 
18. Sarkar U, Karter AJ, Liu JY, Moffet H, Adler NE, Schillinger D. Hypoglycemia is more common among type 2 diabetes patients with limited health literacy: The diabetes study of northern California (DISTANCE). J Gen Intern Med. 2010; 25(9):962-968.

19. Sarkar U, Fisher L, Schillinger D. Is self-efficacy associated with diabetes selfmanagement across race/ethnicity and health literacy? Diabetes Care. 2006;29:823-829.

20. Osborn CY, Cavanaugh K, Wallston KA, White RO, Rothman RL. Diabetes numeracy: An overlooked factor in understanding racial disparities in glycemic control. Diabetes Care. 2009;32:1614-1619.

21. Cutilli, Carolyn. Health literacy in geriatric patients. Orthop Nurs. 2007;26(1):43-48.

22. Schillinger D, Barton LR, Karter AJ, Wang F, Adler N. Does literacy mediate the relationship between education and health outcomes? A study of a low-income population with diabetes. Public Health Rep. 2006;3:245-254.

23. Davis, TC, Long, SW, Jackson, RH, Mayeaux, EJ, George, RB, Murphy, PW, Crouch, MA. Rapid estimate of adult literacy in medicine: A shortened screening instrument. Fam Med. 1993;25:391-395.

24. Parker RM, Baker DW, Williams MV, Nurss JR. The test of functional health literacy in adults: A new instrument for measuring patients' literacy skills. J Gen Internal Med. 1995;10(10):537-41.

25. Weiss BD, Mays MZ, Martz W, Castro KM, DeWalt DA, Pignone MP, Mockbee J, Hale FA. Quick assessment of literacy in primary care: The newest vital sign. Ann Fam Med. 2005;3:514-522.

26. Taylor, W.L. Cloze procedure: A new tool for measuring readability. Journalism Quarterly, 1953. 30; 415-433. 
27. Jastak S, Wilkinson GS. Wide Range Achievement Test-Revised (WRAT-R). San Antonio, TX: The Psychological Corporation. 1984.

28. Baker DW, Williams MV, Parker RM, Gazamararian JA, Nurss JR. Development of a brief test to measure functional health literacy. Patient Educ Couns. 1999;38(1):33-42.

29. Zoellner J, Connell C., Bounds W., Crook L, Yadrick K. Nutrition literacy status and preferred nutrition communication channels among adults in the lower Mississippi delta. Prev Chronic Dis. 2009; 6(4):1-11.

30. Diamond JJ. Development of a reliable and construct valid measure of nutritional literacy in adults. 2007,6:5. Nutrition Journal. http://www.nutritionj.com/content/pdf/1475-28916- . Accessed November 9, 2010.

31. Guthrie JF, Derby BM, Levy AS. What people know and do not know about nutrition. In: Frazeo (Ed), America's Eating Habits: Changes and Consequences. Economic Resource Services, US Department of Agriculture. Agriculture Information Bulletin No. 750. http://www.ers.usda.gov/publications/aib750/aib750m.pdf. 1999. Accessed June 15, 2011.

32. International Food Information Council Foundation. 2011 food \& health survey: Consumer attitudes toward food safety, nutrition \& health; Executive summary \& key trends.http://www.foodinsight.org/Content/3840/FINAL\%20EXECUTIVE\%20SUMMA RY\%202011.pdf. Accessed June 21, 2011.

33. Lynch EB, Holmes S. Food group categories of low-income African American women. $J$ Nutr Educ Behav. 43:157-164, 2011. 
34. American Dietetic Association. Nutrition and you: Trends 2011: Public Opinion on Food and Nutrition: 20 Years of Insights. http://www.eatright.org/nutritiontrends/ . Accessed Nov. 7, 2011.

35. Goodman S, Hammond D, Pillo-Blocka F, Glanville T, Jenkins R. Use of nutritional information in Canada: National trends between 2004 and 2008. J Nutr Educ Behav. 43(5):356-365, 2011.

36. Ollberding N, Wolf R, Contento I. Food label use and its relation to dietary intake among US adults. J Am Diet Assoc. 2010;110(8):1233-1237.

37. Thedford K. Food labels: Who is being educated? J Am Diet Assoc. 2005;105(12):402403.

38. Godwin SL, Speller-Henderson L, \& Thompson T. Evaluating the nutrition label: Its use in and impact on purchasing decisions by consumers. Journal of Food Distribution Research. 2006;37(1):82-86.

39. Lewis JE, Arheart KL, LeBlanc WG, Fleming LE, Lee DJ, Davila EP, Cabán-Martinez AJ, Dietz NA, McCollister KE, Bandiera FC, Clark JD Jr. Food label use and awareness of nutritional information and recommendations among persons with chronic disease. Am J Clin Nutr. Nov 2009;90(5);1351-1357.

40. Levy AS, Fein SB. Consumers' ability to perform tasks using nutrition labels. Journal of Nutrition Education. 1998;30(4):210-217.

41. Kunkel D, McKinley C. Developing ratings for food products: Lessons learned from media rating systems. J Nutr Educ Behav. 39:S25-S31, 2007.

42. Huizinga MM, Carlisle AJ, Cavanaugh KL, et al. Literacy, numeracy, and portion-size estimation skills. Am J Prev Med. 2009;36(4):324-328. 
43. Federal Plain Language Guidelines. December, 2010.

http://www.plainlanguage.gov/howto/guidelines/bigdoc/index.cfm . Accessed April 11, 2011.

44. Wolff K, Cavanaugh K, Malone R, et al. The Diabetes Literacy and Numeracy Education Toolkit (DLNET): Materials to facilitate diabetes education and management in patients with low literacy and numeracy skills. Diabetes Educ. 2009;35:233-245.

45. Tang YH, Pang SMC, Chan MF, Yeung GSP, Yeung VTF. Health literacy, complication awareness, and diabetic control in patients with type 2 diabetes mellitus. $J$ Adv Nurs. 2008;62:74-83.

46. Wallace AS, Seligman HK, Davis TC, et al. Literacy-appropriate educational materials and brief counseling improve diabetes self-management. Patient Educ Couns. 2009;75:328-333.

47. Clement S, Ibrahim S, Crichton N, Wolf M, Rowlands G. Complex interventions to improve the health of people with limited literacy: A systematic review. Patient Educ Couns. 2009;75:340-351.

48. Gibbs HD, Chapman-Novakofski. Exploring nutrition literacy: Attention to assessment and the skills clients need. Health. (Accepted January 18, 2012 for publication) 